\title{
A highly smart MEMS acetone gas sensors in array for diet-monitoring applications
}

\author{
Jae Eun Lee ${ }^{1,2}$, Chan Kyu Lim³ ${ }^{3}$ Hyunjoon Song ${ }^{3}$, Sung-Yool Choi ${ }^{2}$ and Dae-Sik Lee ${ }^{1 *}$ (D)
}

\begin{abstract}
In the present work, gas sensor arrays consisted of four different sensing materials based on $\mathrm{CuO}$ and their depositions on the MEMS microheaters were designed, fabricated and characterized. The sensor array is consisted with $\mathrm{CuO}$, $\mathrm{CuO}$ with Pt NPs, $\mathrm{ZnO}-\mathrm{CuO}$ and $\mathrm{ZnO}-\mathrm{CuO}$ with Au NPs and their gas sensing properties are characterized for detection of exhaled breath-related VOCs. Through MEMS microheaters, power consumption is considered for application to healthcare devices which requires ultrasensitive acetone gas sensitivity. Also, using the principal component analysis, it enables to discriminate acetone gas, a biomarker for fat burning during diet, with other VOCs gases. The device would be applicable for on-site diet monitoring in the field of mobile healthcare.
\end{abstract}

Keywords: Acetone, MEMS heater, CuO-based sensor array, Pattern recognition, Diet monitoring, PCA

\section{Introduction}

Volatile organic compounds (VOCs) include both manmade and naturally occurring organic chemicals which easily evaporate or sublimate from the liquid or solid because of its low boiling point [1]. Recently, VOCs in exhaled breath is also active research field of gas sensors. Exhaled breath contains more than 900 VOCs that are the products of metabolism and these gases such as acetone, $\mathrm{NO}_{2}, \mathrm{NH}_{3}$, and $\mathrm{H}_{2} \mathrm{~S}$ have been acknowledged as key biomarker gases to diagnose various diseases including diabetes, asthma, lung cancer etc. [2-4]. For example, acetone has been studied as a biomarker because of its correlation with fat-burning through ketone body metabolism [5-7]; in the evaluation for type-1 diabetes, its concentration increases from 300 to $900 \mathrm{ppb}$ for healthy people and exceeds $1800 \mathrm{ppb}$ for diabetic patients [5, 7, 8]. Therefore, its examination can potentially become a new standard for diet monitoring. Metal oxide materials, which is commonly used sensing materials for VOCs gas sensor, have advantages of high sensitivity, fast response/

\footnotetext{
*Correspondence: dslee@etri.re.kr

${ }^{1}$ Diagnostic \& Therapeutic Systems Research Section, Welfare \& Medical ICT Research Department, Electronics and Telecommunications Research Institute (ETRI), Daejeon 34129, Republic of Korea

Full list of author information is available at the end of the article
}

recovery time and low cost [9]. However, they have critical drawback of poor selectivity which means they also showed good response to other gases as well as target gas. Also, the concentration of VOCs in exhaled breath is very low as ppb level, it is required to develop ultrasensitive gas sensors to detect the VOCs in exhaled breath. In this paper, we fabricated gas sensors using the synthesized different copper oxide $(\mathrm{CuO})$ based nanomaterials $[10,11]$ and enhanced the gas sensitivity and selectivity. For the operation of $\mathrm{CuO}$ based gas sensors, it is required to be heated to temperatures in the range of $150-300{ }^{\circ} \mathrm{C}$. In this point of view, microheaters have been studied and integrated in the sensor fabrication process since microsized devices are preferred for lower power consumption $[12,13]$. Using complementary metal oxide semiconductor (CMOS) compatible MEMS processing is advantageous for developing the complete sensor platform on a single chip [14].

Principal component analysis (PCA) is a very useful classification technique widely used in the gas-sensing area [15]. The metal oxide semiconductor gas sensors, have an advantage of broad-spectrum responses in themselves. This can meet a strong demand that the products composed of many components may be identified using the sensor array. The PCA method was applied for 
analyzing distribution of high-dimensional sensing data, in which it is possible to examine the characteristics by a dimension reduction through projection onto the chosen principal components. PCA seeks a projection that represents the data effectively in a least-squares sense, in which PCA projects d-dimension data onto a lowerdimension subspace in a way that is optimal in a sumsquared error sense [16].

\section{Design}

Fabrication of sensor arrays on printed circuit board

MEMS microheater was designed and fabricated at ETRI foundry Fab using the CMOS and MEMS fabrication protocols. Four MEMS microheater substrates were bound to the printed circuit board (PCB) through $\mathrm{Au}$ wire bonding. To deposit the sensing materials on MEMS microheater substrate, powder phase sample was mixed

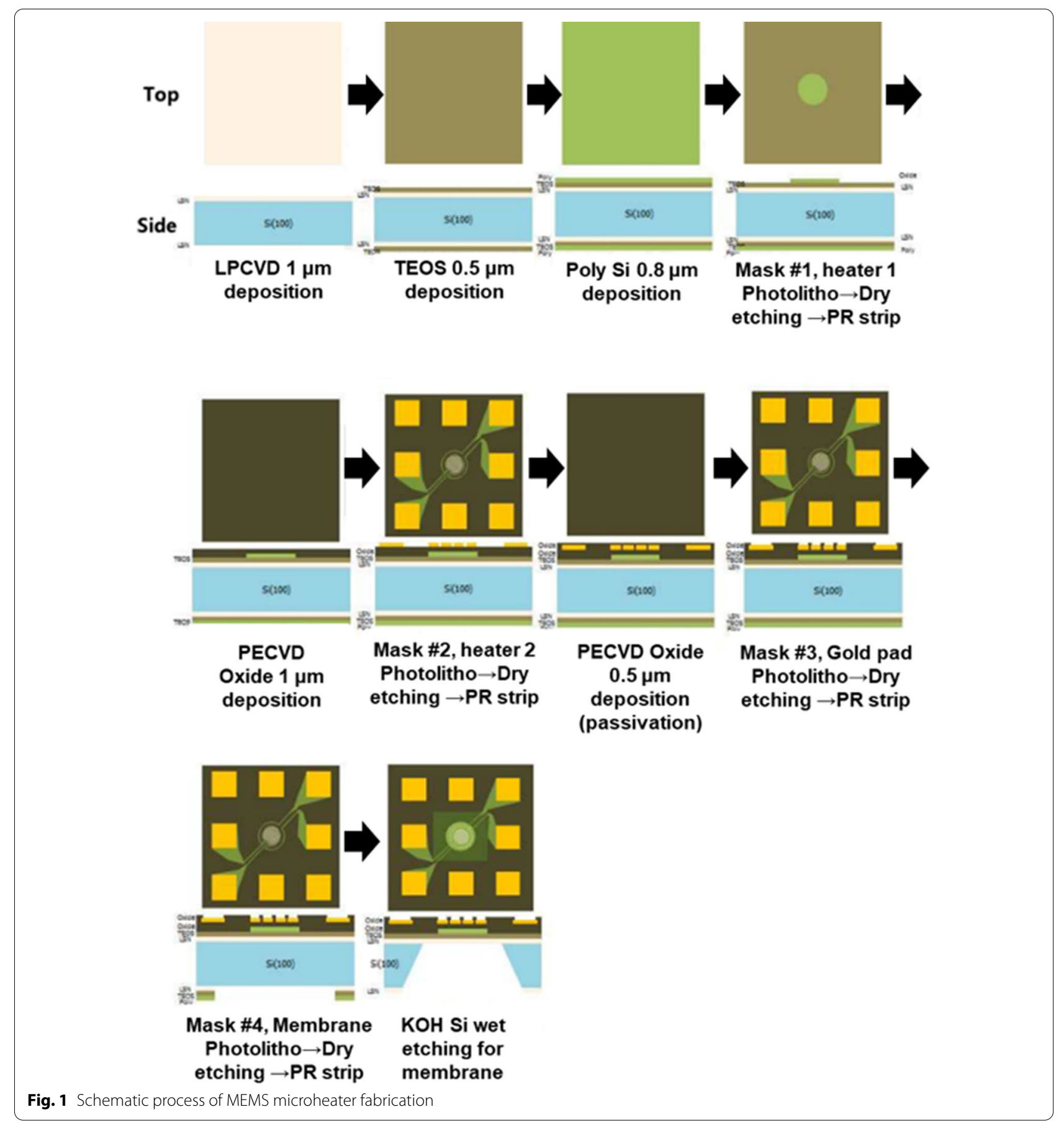




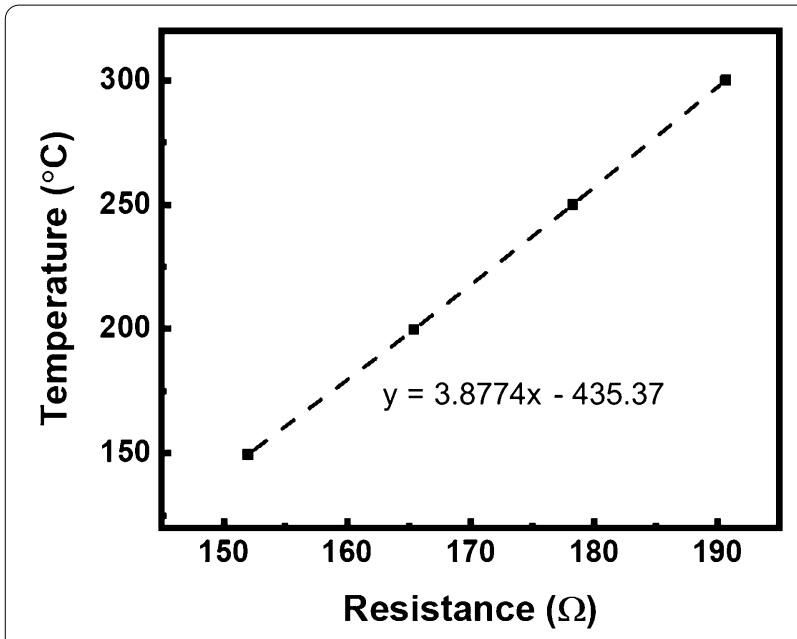

Fig. 2 Resistance characterization of MEMS microheater at various temperature in the furnace system

with the binder and deposited at a specific location using the glass fiber through the optical microscope. HKUST-1 based $\mathrm{CuO}$, HKUST-1 based $\mathrm{CuO}$ with Pt NPs, ZnO$\mathrm{CuO}$ hollow nanocubes and $\mathrm{ZnO}-\mathrm{CuO}$ hollow nanocubes with Au NPs were used as sensing materials and they deposited to the substrate.

\section{Measurements of gas-sensing properties}

Sensing properties were observed using a data-acquisition system (DAQ), having Agilent 34,970 A and the BenchLink Data Logger program, and the sensor arrays were put within a chamber. The balance gas was mixed with dry air and wet air (total $1000 \mathrm{cc} / \mathrm{min}$ ), and analyte gas was obtained from RIGAS Co., Korea at 10-100 ppm. Mass-flow controllers were used to blend analyte gas with a balance to get the concentrations $(100 \mathrm{ppb}$ to $10 \mathrm{ppm}$ ). The gas response was observed by making the gases to flow to the test chamber. And then, the balance gas was flowed to the test chamber to recovery.

\section{Results and discussion}

Figure 1 shows a schematic illustration of the fabrication of micro-hotplate heater. DC voltage was applied to microheater through the power supply and resistance was calculated through Ohm's law. Heater resistance according to certain temperature was characterized in the tube furnace to estimate the temperature of MEMS gas sensors and Fig. 2 shows the resistance characterization of MEMS microheater at various temperature in the furnace system. As shown in Fig. 3, sensing materials were deposited on interdigitated electrodes and four different sensing materials, HKUST-1 based $\mathrm{CuO}, \mathrm{HKUST}-1$ based $\mathrm{CuO}$ with Pt NPs, $\mathrm{ZnO}-\mathrm{CuO}$ core-hollow nanocubes and $\mathrm{ZnO}-\mathrm{CuO}$ core-hollow nanocubes with $\mathrm{Au}$ NPs, were deposited to MEMS microheater substrate and bound to $\mathrm{PCB}$ through $\mathrm{Au}$ wire bonding (Fig. 4).

The responses of $\mathrm{CuO}, \mathrm{CuO}$ with $\mathrm{Pt} \mathrm{NPs}, \mathrm{ZnO}-\mathrm{CuO}$ hollow nanocubes and $\mathrm{ZnO}-\mathrm{CuO}$ hollow nanocubes with Au NPs on MEMS microheater toward acetone, formaldehyde and ethanol are shown in Fig. 4. According to previous data, synthesized $\mathrm{CuO}$ based materials also showed good response to formaldehyde and ethanol not only acetone. Since selectivity of VOCs gas sensors with metal oxide materials is one of the drawbacks to improve, we tried to characterize the sensing properties of these three VOCs gases by the fabrication of sensor arrays and distinguish acetone gas from them. First, response of each $\mathrm{CuO}$ based materials to acetone, formaldehyde and ethanol at different operating temperature was characterized (Figs. 4 and 5). The operating temperature was calculated through $\mathrm{T}=3.8774$ $\mathrm{r}-435.37$, where $\mathrm{r}$ is the resistance of MEMS microheater as calculated in the Fig. 2. The response values were observed at exposure of $1 \mathrm{ppm}$ acetone, formaldehyde and ethanol with dry air condition since acetone concentration within the exhaled breath of the healthy people was assumed to be approximately $1 \mathrm{ppm}$. Among the VOCs, acetone shows the highest response
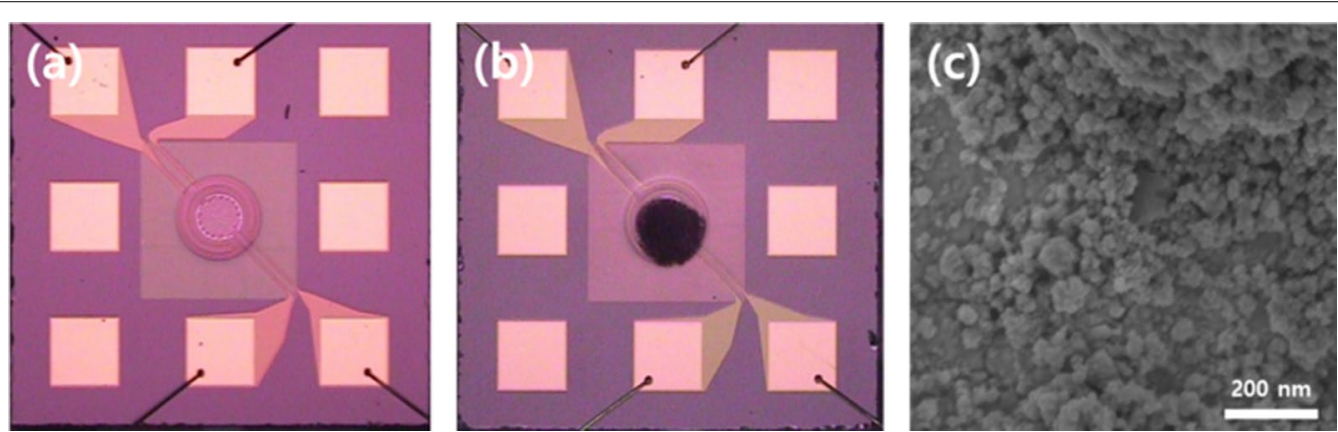

Fig. 3 Optical images of MEMS microheater (a), with deposition of sensing materials (b) and SEM image of deposited sensing material on MEMS microheater (c) 


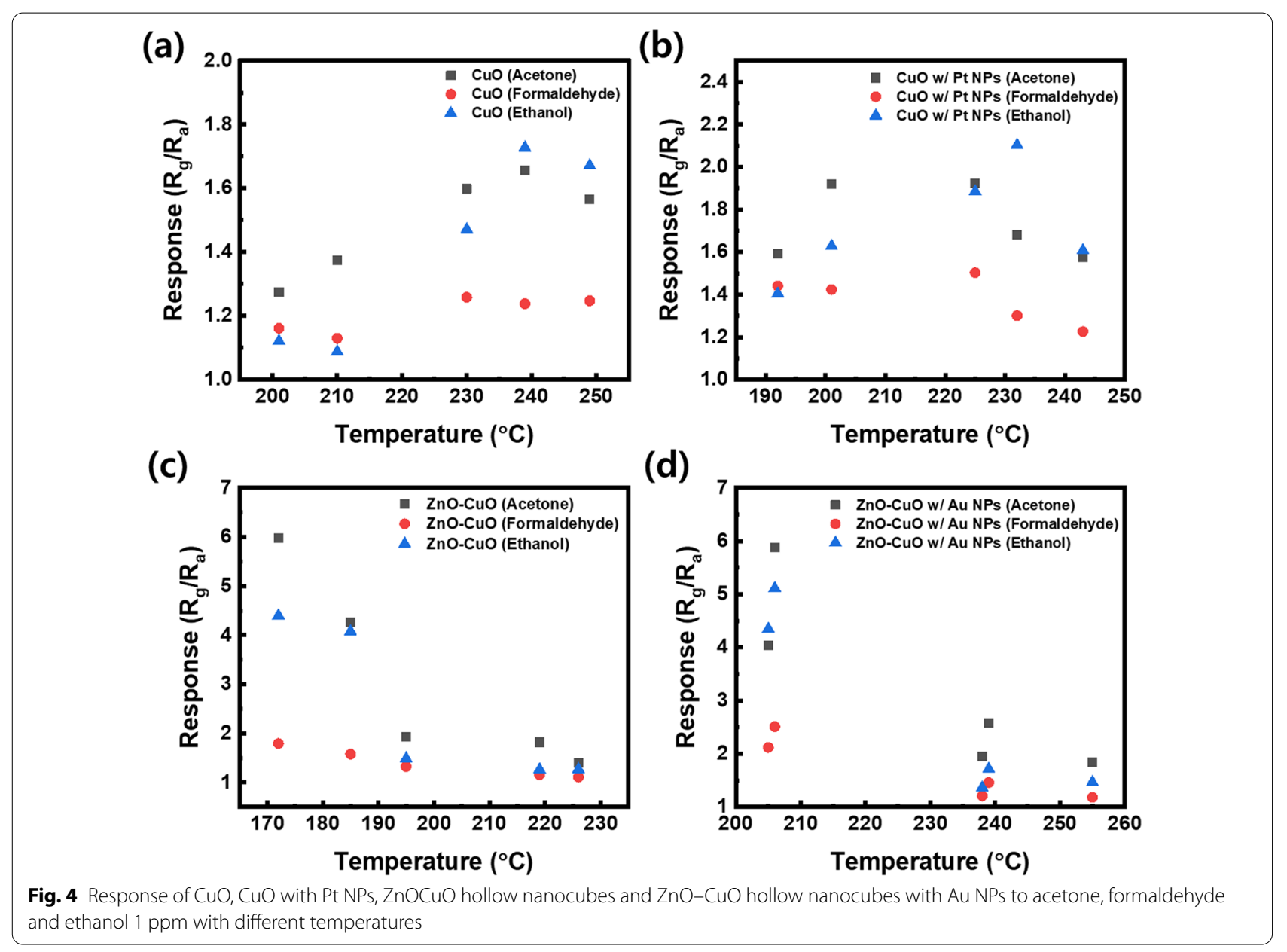

value when the temperature is low as $170{ }^{\circ} \mathrm{C}$ in the case of $\mathrm{ZnO}-\mathrm{CuO}$ hollow nanocubes. Also, other sensing materials shows the highest response to acetone in some cases. To optimize the operating temperature, sensor arrays exposed to $1 \mathrm{ppm}$ acetone with different applied voltages and each sensing materials showed the highest sensitivity at different conditions as shown in Fig. 5. HKUST-1 based $\mathrm{CuO}$ and its noble metal doping materials showed the highest response to acetone when the applied voltage was $2.9 \mathrm{~V}$ (equivalent to about $280{ }^{\circ} \mathrm{C}$ ) while the optimized applied voltage was under $2.4 \mathrm{~V}$ (equivalent to about $190^{\circ} \mathrm{C}$ ) in case of $\mathrm{ZnO}-\mathrm{CuO}$ based materials. The gas response was measured in a wide range of acetone concentrations from 0 to 1500 $\mathrm{ppb}$ and linearity of responses to analyte concentration was observed (Fig. 6). The response can be measured up to $40 \mathrm{ppb}$, and the limit of detection is estimated as $9 \mathrm{ppb}$. Although the response of acetone gas was

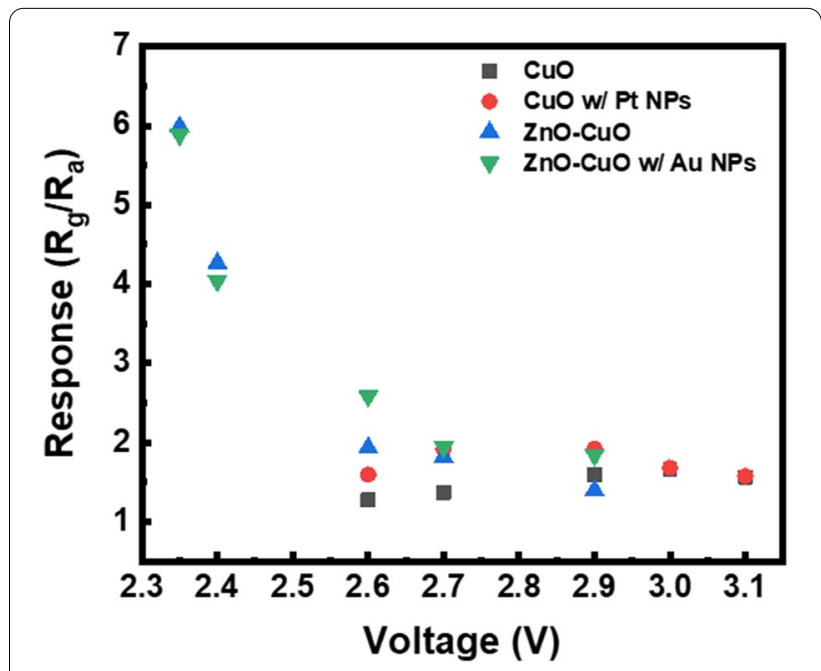

Fig. 5 Response of MEMS sensor arrays for acetone 1 ppm as a function of applied voltage 


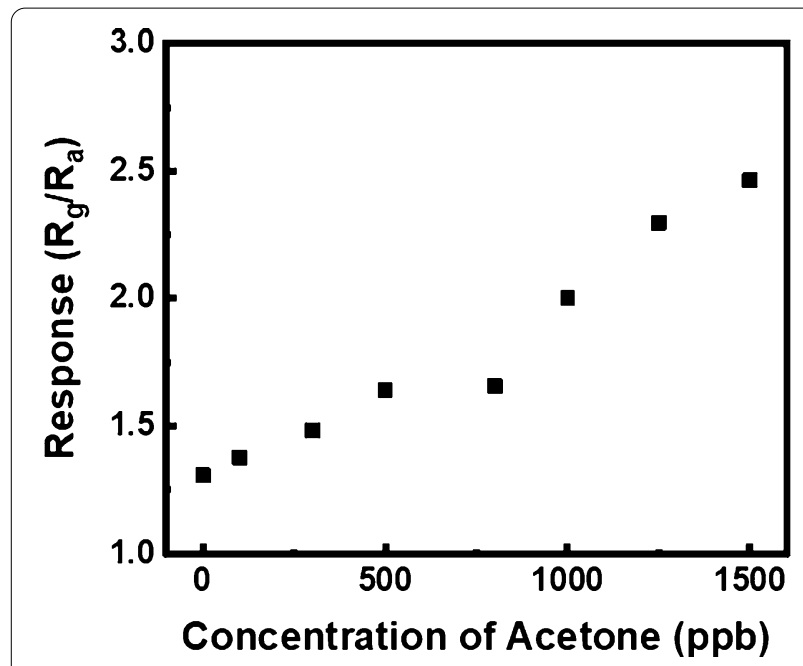

Fig. 6 Response of $\mathrm{ZnO}-\mathrm{CuO}$ hollow nanocubes as a function of acetone concentration

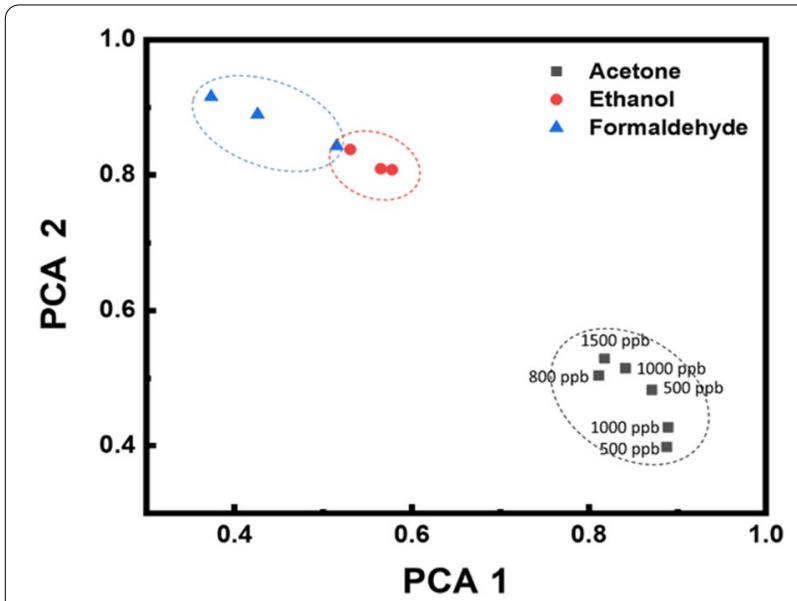

Fig. 7 PCA results of $\mathrm{CuO}$ based sensor arrays

highest among other VOCs gases and optimized conditions for detecting acetone gas was characterized, it is difficult to distinguish acetone with similar structured gases such as ethanol and formaldehyde through response value. Response is dependent to the analyte concentration so that it cannot be distinct parameter for specific gases. As a result, it is required data processing techniques and PCA analysis was used in this paper to show that acetone gas could be distinguished among other test VOCs gases (Fig. 7).

\section{Conclusions}

Sensor arrays consisted of different $\mathrm{CuO}$ based sensing materials was designed and fabricated with MEMS microheaters, and sensing properties were characterized.
Among $\mathrm{CuO}, \mathrm{CuO}$ with Pt NPs, $\mathrm{ZnO}-\mathrm{CuO}$ and $\mathrm{ZnO}-$ $\mathrm{CuO}$ with $\mathrm{Au} \mathrm{NPs}, \mathrm{ZnO}-\mathrm{CuO}$ showed the best response to acetone, and stable operation of our fabricated sensor was confirmed at the humid conditions such as exhaled breath. Through applying MEMS microheater to sensor arrays, power consumption was reduced to $34-50 \mathrm{~mW}$ for each sensor. Also, PCA analysis showed that acetone gas could be distinguished with other test VOCs gases.

\section{Abbreviations}

VOCs: Volatile organic compounds; CMOS: Vomplementary metal oxide semiconductor; MEMS: Micro electronic and mechanical systems; CuO: Copper(II) oxide; ZnO: Zinc oxide; NPs: Nanoparticles; HKUST-1: Copper benzene-1,3,5tricarboxylate; PCB: Printed circuit board; DAQ: Data-acquisition system; PCA: Principal component analysis.

\section{Acknowledgements}

This research was supported by the National Research Foundation of Korea under the research project.

\section{Authors' contributions}

$J E, C G$ and DS performed the device fabrication, experiments, analyzed the data and wrote the manuscript. JE carried out device characterization. $\mathrm{HJ}$, SY and DS supervised the research and reviewed the manuscript. All authors read and approved the final manuscript.

\section{Funding}

This study was supported by Development of a research project program of Development of a Mobile Diet-monitoring Technology based on multiple biomarkers, the National Research Foundation (NRF) of KOREA (NRF2017M3A9F1033056, NRF-2021M3H4A4079271).

\section{Availability of data and materials}

The datasets supporting the conclusions of this article are included within the article.

\section{Declarations}

\section{Competing interests}

The authors declare that they have no competing interests.

\section{Author details}

${ }^{1}$ Diagnostic \& Therapeutic Systems Research Section, Welfare \& Medical ICT Research Department, Electronics and Telecommunications Research Institute (ETRI), Daejeon 34129, Republic of Korea. ${ }^{2}$ School of Electrical Engineering, Korea Advanced Institute of Science and Technology, 291 Daehak-ro, Yuseong-gu, Daejeon 34141, Republic of Korea. ${ }^{3}$ School of Chemistry, Korea Advanced Institute of Science and Technology, 291 Daehak-ro, Yuseong-gu, Daejeon 34141, Republic of Korea.

Received: 30 August 2021 Accepted: 26 October 2021

Published online: 30 October 2021

\section{References}

1. Wang H, Nie L, Li J, Wang Y, Wang G, Wang J et al (2013) Characterization and assessment of volatile organic compounds (VOCs) emission form typical industries. Chin Sci Bull 58:724-730

2. de Lacy Costello B, Amann A, Al-Kateb H, Flynn C, Filipiak W, Khalid T et al (2014) A review of the volatiles form the healthy human body. J Breath Res 8:014001

3. Davies SJ, Spanel P, Smith D (2014) Breath analysis of ammonia, volatile organic compounds and deuterated water vapor in chronic kidney disease and during dialysis. Bioanalysis 6:843-857 
4. Miekisch W, Schubert JK, Noeldge-Schomburg GFE (2004) Diagnostic potential of breath analysis-focus on volatile organic compounds. Clin Chim Acta 347:25-39

5. Deng C, Zhang J, Yu X, Zhang W, Zhang X (2004) Determination of acetone in human breath by gas chromatography-mass spectrometry and solid-phase microextraction with on-fiber derivatization. J Chromatogr B 810(2):269-275

6. Diskin AM, Španěl P, Smith D (2003) Time variation of ammonia, acetone, isoprene and ethanol in breath: a quantitative SIFT-MS study over 30 days. Physiol Meas 24(1):107-119

7. Sulway M, Malins J (1970) Acetone in diabetic ketoacidosis. Lancet 296(7676):736-740

8. Cao W, Duan Y (2006) Breath analysis: potential for clinical diagnosis and exposure assessment. Clin Chem 52(5):800-811

9. Yamazoe N, Shimanoe K (2009) New perspectives of gas sensor technology. Sens Actuators B 138:100-107

10. Lee JE, Kim DY, Lee H-K, Park HJ, Ma A, .Choi S-Y, Lee D-S (2019) Sonochemical synthesis of HKUST-1-based CuO decorated with Pt T nanoparticles for formaldehyde gas-sensor applications. Sens Actuators B 292:289-296
11. Lee JE, Lim CK, Park HJ, Song H, Choi S-Y, Lee D-S (2020) ZnO-CuO corehollow cube nanostructures for highly sensitive acetone gas sensors at the ppb level. ACS Appl Mater Interfaces 12:35688-35697

12. Simon I, Bârsan N, Bauer M, Weimar U (2001) Micromachined metal oxide gas sensors: opportunities to improve sensor performance. Sens Actuators $B$ 73:1-26

13. Mo Y, Okawa Y, Tajima M, Nakai T, Yoshiike N, Natukawa K (2001) Micromachined gas sensor array based on metal film micro-heater. Sens Actuators B 79:175-181

14. Lu C-C, Liao K-H (2000) Microfabrication and chemoresistive characteristics of SBA-15-templated mesoporous carbon gas sensors with CMOS compatibility. Sens Actuators B 143:500-507

15. Lee D-S, Huh J-S, Lee D-D (2003) Classifying combustible gases using micro gas sensor array. Sens Actuators B 93:1-6

16. Duda RO, Hart PE, Stork DG (2012) Pattern classification. Wiley, Hoboken

\section{Publisher's Note}

Springer Nature remains neutral with regard to jurisdictional claims in published maps and institutional affiliations.

\section{Submit your manuscript to a SpringerOpen ${ }^{\circ}$ journal and benefit from:}

- Convenient online submission

- Rigorous peer review

- Open access: articles freely available online

- High visibility within the field

Retaining the copyright to your article

Submit your next manuscript at $\boldsymbol{\nabla}$ springeropen.com 